\title{
The Hope and Adaptation Scale (HAS): Establishing Face and Content Validity
}

\author{
Andrew Soundy ${ }^{1 *}$, Simon Rosenbaum ${ }^{2}$, Tracey Elder ${ }^{1}$, Derek Kyte ${ }^{3}$, Brendon Stubbs ${ }^{4}$, \\ Laura Hemmings ${ }^{5}$, Carolyn Roskell ${ }^{1}$, Johnny Collett ${ }^{6}$, Helen Dawes ${ }^{6}$ \\ ${ }^{1}$ Department of Physiotherapy, School of Sport, Exercise and Rehabilitation Sciences, University of Birmingham, \\ Edgbaston, Birmingham, England \\ ${ }^{2}$ School of Medical Sciences, University of New South Wales, Sydney, Australia \\ ${ }^{3}$ Institute of Applied Health Research, University of Birmingham, Edgbaston, Birmingham, England \\ ${ }^{4}$ Department of Health Service and Population Research, Kings College, London, England \\ ${ }^{5}$ Solihull Mental Health NHS Trust, Birmingham, England \\ ${ }^{6}$ Department of Sport and Health Sciences, Faculty of Health and Life Sciences at Oxford Brookes University, \\ Oxford, England \\ Email: *A.A.Soundy@bham.ac.uk
}

Received 4 March 2016; accepted 10 May 2016; published 13 May 2016

Copyright $(2016$ by authors and Scientific Research Publishing Inc.

This work is licensed under the Creative Commons Attribution International License (CC BY).

http://creativecommons.org/licenses/by/4.0/

\section{(c) (i) Open Access}

\begin{abstract}
Purpose: To develop and test the face and content validity of a scale that assesses an individual's adaptation and expression of hope to a life changing events, disease or trauma. Method: The Hope and Adaptation Scale was developed and tested across three stages. Stage 1 involved the use of a review of literature to conceptually map the tool. Stage 2 required exploratory investigations of the questionnaire by members of an expert panel. Stage 3 assessed the construct validity of the resulting scale. Results: Through the processes of Stage 1 and 2, the tool was developed and reduced to a 3-item scale that assessed a spectrum of hope-related responses and a spectrum of adaptation-related responses. Stage 3 identified fifteen independent health care professionals who assessed the scale. The content validity index of the resultant scale was 0.6 that was above the required level to be acceptable. The hope spectrum responses scored the highest content validity ratio (0.73). Discussion: The proposed scale appears to have face and content validity for application to a various number of events, disease or trauma experiences. Further testing of the scale is required for application in specific population groups.
\end{abstract}

\section{Keywords}

Face Validity, Content Validity, Adaptation, Hope

\footnotetext{
${ }^{*}$ Corresponding author.
}

How to cite this paper: Soundy, A., Rosenbaum, S., Elder, T., Kyte, D., Stubbs, B., Hemmings, L., Roskell, C., Collett, J. and Dawes, H. (2016) The Hope and Adaptation Scale (HAS): Establishing Face and Content Validity. Open Journal of Therapy and Rehabilitation, 4, 76-86. http://dx.doi.org/10.4236/ojtr.2016.42007 


\section{Introduction and Rationale for Project}

An individual's expression of hope is a natural response to a situation where there is temptation to despair. Hope that prevails is influenced by, and intertwined with, one's ability to accept their situation, where an embracement of the situation can allow consolidation with it eventually [1]. The expression of hope and adaptation are central to whether an individual is able to cope with, or succumb to, a given situation, such as a chronic illness [2]. These expressions are related to a spectrum of hope-related responses, ranging from no hope to concrete hope. For adaptation, a spectrum of responses ranges from rejection or denial to embracement [2]-[5]. Critical and central to the hope spectrum is hope in possibility. This is identified as a type of hope which allows and embraces uncertainty in a positive way, enabling the individual to accept that what might be hoped for, may not occur [6]. This in turn aids an individual's ability to be defiant and motivated towards goals without a "concrete" need to achieve them. This is important because an individual's belief that something could be accomplished is a strong predictor life satisfaction [7]. A central aspect of hope in possibility is that an individual can accept an uncertain or unknown future; this directly links to, and includes, an adaptive expression.

Within, and central to, the adaptation spectrum of responses is the concept of acknowledgement. Acknowledgement exists and is expressed in the process of adaptation before an individual embraces or fully accepts what has happened within their present situation [8]. Acknowledgement provides patients with some psychological distance from what has happened and reflects knowing the problem exists within their present circumstances, without embracing it or resigning oneself to it. Further to this, it is often associated with not thinking too far ahead into the future with the implications of this [9]. Both hope in possibility and acknowledgement are so important because they illustrate the ability of the person to acknowledge the meaning and impact of an event, disease or trauma (EDT) in the present and in the future. For instance, the meaning and impact on one's interactions, relationships and meaningful and valued activities, can underpin some of the most important levels of generalised hope [10]. Furthermore, being able to (re)initiate such valued interactions and activities are also hopepromoting.

The ability to (re)engage and access meaningful interactions and activities, including one's paid employment, sporting group, or social group, directly impacts an individual's mental well-being [11]-[13]. Importantly, both being able to accept and have hope in possibility are important predictors of mental well-being. For instance, acceptance has been associated with the pursuit of normal life activities in patients with chronic pain [14]. Alternatively, following severe burns in children, hope has been positively and significantly associated with selfworth, as well as positively reducing problematic behaviours [15]. Moreover, hope and adaptation [16]-[19] have been identified as significant predictors of adherence in medical interventions, highlighting the importance of measuring and targeting these aspects in the healthcare setting.

Whilst it is important to consider hope it is also important to consider the need for a measure that can capture experiences of hopelessness. The main reason for this is because hopelessness can follow the experience of severe and significant consequences of a disease or illness [20]. Further to this several factors may increase the chances of experiencing hopelessness including: (1) the incurable nature of the chronic illness [21] and struggling with the perception of life a never-ending battle [22] and (2) not being able to see the possibility of changing ones future or seeing the future in a biased way [23]. Identifying a simple clinical tool that can identify and provide further understanding between hopelessness and psychological adaptation and being able to document responses to treatment would seem vital based on this current understanding.

Previous clinical tools that consider hope have several items for instance the Herth Hope Index has 12 items [24], or are based on particularised hopes (specific hopes, linked to goals that include agency and pathways) [25] rather than generalised hopes. Further, it is also noted that several items are often included for adaptation scales [26], yet are often time-consuming to administer and thus the clinical utility and applicability of the tools are to some extent limited by time governed within hospital setting or other pressured environments. A clinical tool incorporating a simple scale, that could be completed quickly, would give patients and clinicians alike a chance to monitor changes in adaptation and hope, that accompany events which affect an individual's mental wellbeing and hope. This study therefore seeks to develop a suitable questionnaire, based on previous literature, expert opinion and construct validity assessment.

\subsection{Principle Research Question}

Can a questionnaire that considers generalised hopes of individuals with chronic illnesses be developed to assess 
their ability to cope with the illness or succumb to it?

\subsection{Research Objectives}

- To iteratively develop a clinical scale to identify the vulnerability of individuals with chronic illness, in succumbing to despair and hopelessness following exposure to an EDT.

- To determine the face and content validity of the proposed scale

\section{Methods}

\subsection{Methodology}

This study was based on a guidance framework for validation studies [27]. The face and construct validity was established through three stages [28] [29]. These stages included: (1) a review of the literature, (2) exploratory investigations with members of the expert panel to develop the items to be included in the questionnaire for assessment, and (3) an online questionnaire, used to assess the content validity of the selected questions.

\subsection{Stage 1: The Review of Literature and Concept Mapping of the Tool}

The first author undertook a narrative review of literature. Review articles were identified from the author's personal database. Reviews were included if: (a) the aims and focus of the review included any concepts from a recently developed model of psychological adjustment, emotion and hope [2]. The reason for this was that it was noted that all or the majority components of the model were identified within research considering multiple and varied chronic illnesses [9] [30]. For instance, all major components of the model appear to be identified in populations including motor neurone disease, stroke, spinal cord injury and multiple sclerosis (b) Reviews were included if they included qualitative studies and considered patients with chronic illnesses. (c) Reviews were included if they were positioned as "subtle realist" or "critical realist". The reasons for this is that previous reviews [9] [10] [12] [30]-[32] using such "positions" have been able to identify common experiences, processes and factors that influence experiences. By combining a number of such reviews it was considered that more generalizable concepts would be identified and that a subsequent scale developed from such support from such an evidence base would likely be more robust or trustworthy. This was important because the development of a scale had to be robust and have the potential to be generalisable.

\subsection{Stage 2: Exploratory Investigations of the Questionnaire with Members of the Expert Panel}

\subsubsection{Procedure: Survey to Establish Face Validity}

An online survey (qualtrics.com) was set up to consider the face validity of the initial tool and provide ideas for development. The survey considered two domains: (1) demographical information which included; gender, age, area of expertise, professional group, and years worked in main clinical/research area. (2) Domain 2 considered open and closed questions identifying, developing and assessing the proposed scale area of focus and content. The scale development questions included; (a) if the questions asked would relate to the main group of patients they worked with (yes/no, with opportunity to explain), (b) if they would use the scale for the purpose of research or clinical practice (yes/no), (c) awareness of other scales that may already exist that capture the same content, (d), what are the main observations about the scale and are there any changes that could be suggested, (e) are there any areas or items of the scale that could be removed and (f) are the any areas or items of the scale that could be added.

\subsubsection{Eligibility Criteria and Sampling Method}

A purposive sample of individuals was selected to be part of the expert panel. The primary author sent 15 individual email requests to become a member of the expert panel. The individuals were identified as having extensive clinical experience and patient contact within different areas of practice. To be included on the expert panel individuals had to have at least 5 years clinical and/or academic experience including patient contact from a range of clinical specialities. Two clinicians were targeted to increase the breath of expertise and two individuals with expertise in the development of outcome measures and validation studies were identified. 


\subsubsection{Procedure: Outcome Tool Development}

The tool was developed across 3 rounds (from January 2016 to March 2016). Round 1 established the areas of investigation that could be considered for the initial version of the tool using a structured survey (see above). This identified the key areas to focus on and requirements and suggestions for modification of the proposed tool. Individuals were emailed the tool and required to respond within a period of a month. Two reminder emails were sent after a period of a week and 2 weeks. Round 2 provided a chance to make major modifications to the revised tool, individual emails were sent with the revised tool details and requests were made to consider the tool for revision within a period of 2 weeks. Round 3 repeated the same procedure as round two but was an opportunity to make minor modifications to the scale and once ready assess the construct validity within stage 3.

\subsubsection{Ethics}

Ethical approval was obtained from the University of Birmingham (ethics reference number (ERN_15-0545).

\subsection{Stage 3: Assessment of Construct Validity}

A convenience sample of clinicians was asked to assess the validity of each item of the scale.

\subsubsection{Procedure}

An online survey was used to consider the content validity [33] of each item for the final questionnaire. Participants were asked to consider each item and assess if the item (question posed) was deemed important enough to be included in the questionnaire. Individuals were able to respond using a likert scale response, which included three answers; (a) this is an essential question, (b) this is a useful but not essential question, and (c) this question is not necessary.

\subsubsection{Eligibility Criteria and Sampling Method}

A convenience sample of clinicians were included if: (a) They work with individuals who have suffered the following chronic illnesses: motor neurone disease; stroke; multiple sclerosis; Parkinson's disease; COPD; chronic pain; cardiac rehabilitation; arthritis; severe and enduring mental illness. (b) Had an interest and feel able to comment and rate the items used in the assessment. (c) Considered their experience working with patients expectations, goals or hopes. Finally (d) had at least a year's clinical experienced patients with major depression and other mood disorders.

\subsection{Analysis}

Descriptive statistics and content analysis were undertaken. Responses were pooled and the number indicating essential for each item was documented. A content validity ratio (CVR) of all questions/items individuals was calculated, as well as a mean of all items (Content Validity Index: CVI). The validity of each question/item and an overall rating was thus made based on the CVR and CVI. The minimum score required for the CVI was determined by a pre-existing table for interpretation [33].

\section{Results}

\subsection{Stage 1}

Broad consideration from previously published literature that had considered the expression and levels of hope was identified [2] [5] [9] [10] [30] [31]. One study [34] duplicated information so was removed. Table 1 provides a summary table of the content of the included reviews. There were a total of 170 articles and 2319 participants included across all the reviews. The reviews included articles considering Motor Neurone disease, Stroke, Multiple Sclerosis, Parkinson's and Schizophrenia. The common elements relating to psychological adaptation, hope and emotions which may predict the ability of a patient to cope with their EDT were identified as follows; (1) a perceived ability to cope, (2) an ability to adapt to the EDT and be able to express hope following the EDT, (3) the levels of generalised hope, (4) vulnerability to common factors which effect an individual's hope. The initial scale shown and evaluated in stage 2 round 1 was a scale was identified based on these elements combined. The scale development can be requested from the primary author. 
Table 1. A Summary of included review studies.

\begin{tabular}{|c|c|c|c|}
\hline Study & Review type & Methods & $\begin{array}{l}\text { Key findings relating to psychological } \\
\text { adaptation, emotion and hope }\end{array}$ \\
\hline $\begin{array}{l}\text { Soundy } \\
\text { et al. [2] }\end{array}$ & $\begin{array}{c}\text { Systematic review } \\
\text { and thematic } \\
\text { synthesis }\end{array}$ & $\begin{array}{l}\text { Total number of studies: } 47 \\
\text { Chronic illnesses included: } \\
\text { Multiple sclerosis } \\
\text { Total included participants: } \\
1146 \text { ( } 812 \text { females, } 265 \text { males, } \\
\text { and } 69 \text { unknown) } \\
\text { Average age: } 49 \text { years } \\
\text { (30/47 studies) } \\
\text { Average time since } \\
\text { diagnosis: } 12.3 \text { years } \\
\text { (28/47 studies) }\end{array}$ & $\begin{array}{l}\text { Adaptation Related Reponses } \\
\text { Adaptive responses related to a spectrum of response } \\
\text { around the concept of acknowledgement, from transcendence } \\
\text { or embracement to rejection or denial. } \\
\text { Hope Responses } \\
\text { Full spectrum of hope related responses were identified } \\
\text { around the concept of hope, from concrete or certain } \\
\text { hope to no hope or an inability to hope. } \\
\text { Emotional Response } \\
\text { Identifiable distinct emotional states were documented. } \\
\text { This illustrated a spectrum of emotions expressed by participants. } \\
\text { Key emotions associated with hope and adaptive responses. } \\
\text { There was a prevalence of pleasant activated responses } \\
\text { and unpleasant de-activated response identified. }\end{array}$ \\
\hline $\begin{array}{l}\text { Soundy } \\
\text { et al. [5] }\end{array}$ & Meta-ethnography & $\begin{array}{l}\text { Total number of studies: } 10 \\
\text { Chronic illnesses included: } \\
\text { Spinal cord injury, } \\
\text { stroke, multiple sclerosis } \\
\text { Total included participants: } 102 \\
\text { Aggregated age: not given. } \\
\text { Aggregated time since } \\
\text { diagnosis: not given. }\end{array}$ & $\begin{array}{l}\text { Adaptation Related Reponses } \\
\text { Acceptance was identified as central concept to well-being } \\
\text { where extreme expressions of adaptation focus on rejection } \\
\text { or denial related responses. Hope as a paradox (see below) } \\
\text { could also illustrate adaptive responses. } \\
\text { Hope Responses } \\
\text { Hope described in different ways; (1) as a dichotomy from } \\
\text { no hope to concrete hope, (2) as a paradox (the expression } \\
\text { of hope contains and is associated with acceptance and } \\
\text { simultaneously defiance), which contained loss related expressions, } \\
\text { hope as possibility and active hope or hopes relating to challenges. } \\
\text { (3) Hope as transcendence was identified where embracement } \\
\text { of what happens occurs and/or changes in patients' values. } \\
\text { Different factors can influence hope, including } \\
\text { environmental, internal or social. } \\
\text { Emotional Response } \\
\text { Emotions associated with hope and adaptation responses. } \\
\text { Emotional response may be less after time. }\end{array}$ \\
\hline $\begin{array}{l}\text { Soundy } \\
\text { and } \\
\text { Condon } \\
\text { [9] }\end{array}$ & $\begin{array}{l}\text { Systematic review } \\
\text { with thematic } \\
\text { synthesis }\end{array}$ & $\begin{array}{l}\text { Total number of studies: } 29 \\
\text { Chronic illnesses included: } \\
\text { Motor Neurone Disease } \\
\text { Total included participants: } \\
342 \text { patients diagnosed with } \\
\text { MND (175 male, } 117 \text { female, } \\
50 \text { unknown) } \\
\text { Aggregated age: not reported. } \\
\text { Aggregated time since } \\
\text { diagnosis: not reported. }\end{array}$ & $\begin{array}{l}\text { Adaptation Related Reponses } \\
\text { Association between hope, adaptation and coping was identified. } \\
\text { Acceptance was identified as a critical response and related } \\
\text { spectrum adaptation responses were identified. Self-determined } \\
\text { responses were distinguished from disease controlling } \\
\text { responses within a model of hope enablement. } \\
\text { Hope Responses } \\
\text { Model of hope enablement established with succumbing response } \\
\text { and coping responses implicated. Critical factors that } \\
\text { influence hope/hopelessness identified including; interactions } \\
\text { and relationships, internal psychological factors and negative } \\
\text { emotions. A hope spectrum response was identified. Generalised } \\
\text { and particularised hopes identified. Hope responses linked } \\
\text { to coping responses. } \\
\text { Emotional Response } \\
\text { Shock related emotions identified and associated with } \\
\text { adaptive responses and hope related responses of individuals. }\end{array}$ \\
\hline $\begin{array}{l}\text { Soundy } \\
\text { et al. [10] }\end{array}$ & Narrative review & $\begin{array}{l}\text { Total number of studies: } 10 \\
\text { Chronic illnesses included: } \\
\text { Stroke } \\
\text { Total included participants: } \\
110 \text { ( } 44 \text { male, } 68 \text { female) } \\
\text { Aggregated age: not given. } \\
\text { Aggregated time } \\
\text { since diagnosis: not given. }\end{array}$ & $\begin{array}{l}\text { Adaptation Related Reponses } \\
\text { The paradox of chronic illness identified the } \\
\text { spectrum of adaptive expressions. } \\
\text { Hope Responses } \\
\text { Spectrum of hope related responses identified as well as } \\
\text { responses relating to the paradox of chronic illness. } \\
\text { A generalised hope framework was identified. Factors that } \\
\text { influence hope/hopelessness including environmental, political, } \\
\text { internal and psychological as well as social identified. } \\
\text { Emotional Response } \\
\text { Shock related emotions identified and associated } \\
\text { with hope and adaptation. }\end{array}$ \\
\hline
\end{tabular}




\section{Continued}

\begin{tabular}{|c|c|c|c|}
\hline $\begin{array}{l}\text { Soundy } \\
\text { et al. [30] }\end{array}$ & Meta-ethnography & $\begin{array}{l}\text { Total number of studies: } 37 \\
\text { Chronic illnesses included: } \\
\text { Parkinsons } \\
\text { Total included participants: } \\
582 \text { individuals (male }=246 \text {, } \\
\text { female = 192, unknown = 124) } \\
\text { Aggregated age: } 70 \text { years } \\
\text { Aggregated time since } \\
\text { diagnosis: not given. }\end{array}$ & $\begin{array}{l}\text { Adaptation Related Reponses } \\
\text { A full spectrum of adaptation related responses were identified } \\
\text { from embracement to rejection responses. Critical identification } \\
\text { for the role of acknowledgement and acceptance. Factors that } \\
\text { influence adaptation and hope identified including internal } \\
\text { psychological, physical and social factors were identifed. } \\
\text { Hope Responses } \\
\text { Internal psychological, social and religious factors that influence } \\
\text { hope/hopelessness were identified. The association between } \\
\text { hope and adaptation was identified. A model of hope was provided. } \\
\text { Emotional Response } \\
\text { Emotional responses identified and were linked } \\
\text { with adaptation related responses. }\end{array}$ \\
\hline $\begin{array}{l}\text { Soundy } \\
\text { et al. }[31]\end{array}$ & Narrative review & $\begin{array}{l}\text { Total number of studies: } 17 \\
\text { Chronic illnesses included: } \\
\text { Stroke }(\mathrm{n}=10) \text { and } \\
\text { Spinal Cord Injury }(\mathrm{n}=7) \\
\text { Total included participants: } \\
\text { not identified. } \\
\text { Aggregated age: not given. } \\
\text { Aggregated time since given: }\end{array}$ & $\begin{array}{l}\text { Adaptation Related Reponses } \\
\text { Acceptance and transcending views of illness } \\
\text { identified as critical factors that influence hope. } \\
\text { Hope Responses } \\
\text { Factors that influence hope/hopelessness were identified and } \\
\text { included internal psychosocial, social and environmental/political. } \\
\text { Emotional Response } \\
\text { Distinct emotions were identified, including mainly unpleasant } \\
\text { emotions. The adaptation response linked to patients' emotions. }\end{array}$ \\
\hline $\begin{array}{l}\text { Soundy } \\
\text { et al. [32] }\end{array}$ & $\begin{array}{l}\text { Systematic } \\
\text { review with } \\
\text { thematic synthesis }\end{array}$ & $\begin{array}{l}\text { Total number of studies: } 20 \\
\text { Chronic illnesses included: } \\
\text { Schizophrenia } \\
\text { Total included participants: } 585 \\
\text { Aggregated age: not given. } \\
\text { Aggregated time since } \\
\text { diagnosis: not given. }\end{array}$ & $\begin{array}{l}\text { Adaptation Related Reponses } \\
\text { Acceptance and transcendence or value changes were } \\
\text { identified as critical factors that influence recovery. } \\
\text { Hope Responses } \\
\text { Factors that influence hope/hopelessness were identified } \\
\text { including internal psychological, social and environmental. } \\
\text { The importance of hope was identified for patients. } \\
\text { Emotional Response } \\
\text { Some negative distinct emotions were identified within review. }\end{array}$ \\
\hline
\end{tabular}

\subsection{Stage 2}

Within the first round, the expert panel judged the originally proposed scale to be too long and to be covering too broader areas of work. Essential domains of assessment were identified as adaptation and hope and it was considered the questionnaire had to allow a patient to identify their own problem. Given this, the scale was reduced to three essential questions (see Appendix 1) which were assessed in round 2 and 3. No major changes were made to the scale following its proposal, rather minor wording and typographical changes were identified in both rounds. This final version of the scale was sent to the expert panel to check wording and accuracy. Given the above, the final three questions considered: (1) Identifying the aspect of adaptation that was most difficult to deal with, (2) identifying if the individual was hopeful that this chosen aspect could be overcome in the future, and (3) identifying if they perceived themselves able to adapt to this situation. Appendix 1 provides the final questionnaire. Supplementary file 1 provides details of the scoring of the questionnaire.

\subsection{Stage 3}

Sixteen health care professionals (8 female, with a mean age of $37.4 \pm 10.6$ years and mean clinical experience of $8.9 \pm 5.3$ years, comprising 9 physiotherapists, 1 nurse, 2 psychologists, 1 occupational therapist, 1 speech and language therapist and 2 other health professionals, completed the assessment. Individuals were working in the following areas: neurology $(n=3)$, mental health $(n=5)$, musculoskeletal practice $(n=3)$, respiratory $(n=$ $1)$, other $(n=4)$ and completed a rating of each question from the scale.

The CVR for question 1 , naming the difficulty, was 0.63 with $13(13 / 15,81 \%)$ respondents identifying it as an essential question. The CVR for question 2, identifying the hope associated with the situation, was 0.75 with $14(14 / 16,88 \%)$ of respondents identifying it as an essential question. The CVR for question 3, identifying the ability to adapt to the difficulty, was 0.5 with $12(12 / 16,75 \%)$ of respondents identifying it as an essential question. Given the above CVR scores, the overall CVI for the scale was 0.63 , which was above the minimal acceptable value of 0.49 [33]. 


\section{Discussion}

The current study has developed a brief scale that is able to capture essential self-defined ratings of adaptation and hope, and is able to consider the effects of loss generated from an EDT. The content validation demonstrates the scale has face validity and acceptable levels of content validity. Interestingly the content validation identified higher ratings for the hope item and lower ratings for the adaptation item.

\subsection{Practical Application of the HAS}

The primary application of the scale, based on the previous publications used to develop the scale (see stage 1), for individuals who have suffered a chronic neurological illness. However, given that the concepts identified are relevant within a wide range of illness such as sickle cell disease [35], obesity [36], cancer [37], heart failure [38], palliative illness [39], and schizophrenia [40], the scale is likely to have applicability across multiple chronic and palliative conditions. It is likely that application of the scale during times of uncertainty, for example during diagnostic procedures or when an event is recently experienced, may be an important focus of this tool to capture initial changes. For instance, alongside the importance of hope and adaptation during the diagnostic procedure of MS, particular emotions are prevalent in patients and influenced by interactions and access to information [41].

For the clinician, both the spectrum of hope and adaptation responses can be identified as underlying common narratives identified from patients who suffer from chronic illness, for example, of 13 common narratives identified within patients who have suffered a neurological disease [5], each has an underlying consideration towards the expression hope and adaptation [42]. Thus, clinicians can: (a) use and offer stories knowing that they have potential to influence a patient's hope, adaptation and mental well-being, and (b) that if following any concern regarding the mental well-being of patients, it is possible to capture these expressions by using the HAS.

The choice given to the patient regarding the difficulty they are experiencing, means the scale may have much broader application than just chronic illness. For instance, the application of the scale could be utilised with other stakeholders affected by an EDT, such as children, partners and parents of individual with traumatic brain injuries as they also experience difficulty adjusting and coping with the condition [43]. Alternatively, hope is needed for family members of patients who are in a coma [44]. Furthermore, the scale could also be used in conjunction with particular situations that require adaptation, for instance potential job change or loss, loss or death of a close relative or friend.

The wording of the scale links to the most difficult factor the patient is experiencing. However, it is possible multiple difficulties could be identified. Due to the simplicity of the scale and time required to complete it would be possible for a clinician to use the scale in this way. The ability to study and consider what is meaningful and provides enjoyment for the patient is essential for the patient's mental well being [2] as well as considering goals and the patients intrinsic motivation for rehabilitation [45]. Further work is needed to establish the benefit of this.

Previous theory in the area has identified the importance of both a cognitive and emotional response to illness [46]. With this in mind, being able to capture emotions alongside adaptation and hope would be useful and is represented by the model of emotion adjustment and hope [2]. This model uses the circumplex model of affect [47] alongside adaptation and hope, in order to document a fuller understanding of adaptation over acute and chronic periods. One reason this is so important is because the perception that chronic illness can drastically affect an individual's life and create negative emotional responses that lead to coping that is passive including experiencing feelings of hopelessness [48]. Thus being able to capture all of these dimensions would aid this.

\subsection{Limitations}

The scale has been generated primarily based on a body of literature that considers chronic illness in patients with neurological conditions. The application outside these studies is dependent upon validation in different populations and with established psychometrically supported clinical tools.

\subsection{Conclusion}

The HAS scale appears to have face validity and adequate content validity. The application of the scale is potentially wide and has the potential to be validated in other populations following a varied nature of events, diseases and conditions which influence or challenge individual's mental well-being. 


\section{References}

[1] Marcel, G. (1951) Homo Viator: Introduction to a Metaphysics of Hope. Henry Regnery, Chicago, 29-31.

[2] Soundy, A., Roskell, C., Elder, T., Collett, J. and Dawes, H. (2016) The Psychological Processes of Adaptation and Hope in Patients with Multiple Sclerosis: A Thematic Synthesis. Open Journal of Therapy and Rehabilitation, 4, 22-47. http://dx.doi.org/10.4236/ojtr.2016.41003

[3] Soundy, A., Smith, B., Butler, M., Minns-Lowe, C., Dawes, H. and Windward, C.H. (2010) A Qualitative Study in Neurological Physiotherapy and Hope: Beyond Physical Improvement. Physiotherapy Theory and Practice, 26, 79-88. http://dx.doi.org/10.3109/09593980802634466

[4] Soundy, A., Benson, J., Dawes, H., Smith, B., Collette, J. and Meaney, A. (2012) Understanding Hope in Patients with Multiple Sclerosis. Physiotherapy, 98, 349-355. http://dx.doi.org/10.1016/j.physio.2011.05.003

[5] Soundy, A., Smith, B., Dawes, H., Pall, H., Gimbrere, K. and Ramsay, J. (2013) Patients Expression of Hope and Illness Narratives in Three Neurological Conditions: A Meta-Ethnography. Health Psychology Review, 7, 177-201. http://dx.doi.org/10.1080/17437199.2011.568856

[6] Soundy, A., Sayers, J., Stubbs, B. and Roskell, C. (2014) Don’t Take My Hope Away: Understanding the Patient's Hope in Neurological Rehabilitation. International Journal of Therapy and Rehabiliation, 21, 257-258. http://dx.doi.org/10.12968/ijtr.2014.21.6.257

[7] Bailey, T.C., Eng, W., Frisch, M.B. and Synder, C.R. (2007) Hope and Optimism as Related to Life Satisfaction. The Journal of Positive Psychology, 2, 168-175. http://dx.doi.org/10.1080/17439760701409546

[8] Livneh, H. and Antonak, R.F. (1997) Psychosocial Adapation to Chronic Illness and Disability. Aspen, Maryland.

[9] Soundy, A. and Condon, N. (2015) Understanding How Mental Well-Being Can Be Maintained within Motor Neurone Disease: A Thematic Synthesis. Frontiers in Psychology, 6, 606. http://dx.doi.org/10.3389/fpsyg.2015.00606

[10] Soundy, A., Stubbs, B., Liles, C. and Roskell, C.A. (2014) Identifying a Framework for Hope in Order to Establish the Importance of Geralised Hopes for Individuals Who Have Suffered a Stroke. Advances in Medicine, 471874, 1-8. http://dx.doi.org/10.1155/2014/471874

[11] Hawkins, C., Coffee, C. and Soundy, A. (2014) Considering How Athletic Identity Assists Adjustment to Spinal Cord Injury: A Qualitative Study. Physiotherapy, 100, 268-274. http://dx.doi.org/10.1016/j.physio.2013.09.006

[12] Hole, E., Stubbs, B., Roskell, C. and Soundy, A. (2014) The Patient's Experience of the Psychosocial Process That Influences Identity Following Stroke Rehabilitation: A Metaethnography. The Scientific World Journal, 2014, Article ID: 349151. http://dx.doi.org/10.1155/2014/349151

[13] Soundy, A., Freeman, P., Stubbs, B., Probst, M., Coffee, P. and Vancampfort, D. (2014) The Transcending Benefits of Physical Activity for Individuals with Schizophrenia: A Systematic Review and Meta-Ethnography. Psychiatry Research, 220, 11-19. http://dx.doi.org/10.1016/j.psychres.2014.07.083

[14] McCracken, L.M., Vowles, K.E. and Eccleston, C. (2004) Acceptance of Chronic Pain: Component Analysis and a Revised Assessment Method. Pain, 107, 159-166. http://dx.doi.org/10.1016/j.pain.2003.10.012

[15] Barnum, D.D., Snyder, C.R., Rapoff, M.A., Mani, M.M. and Thompson, R.R. (1998) Hope and Social Support in Psychological Adjustment of Children Who Have Survived Burn Injuries and Their Matched Controls. Children's Health Care, 27, 15-30. http://dx.doi.org/10.1207/s15326888chc2701_2

[16] Berg, C.J., Rapoff, M.A., Snyder, C.R. and Belmont, J.M. (2007) The Relationship of Children’s Hope to Pediatric Asthma Treatment Adherence. The Journal of Positive Psychology, 2, 176-184. http://dx.doi.org/10.1080/17439760701409629

[17] Fraser, C., Hadjimichael, O. and Vollmer, T. (2001) Predictors of Adherence to Copaxone Therapy in Individuals with Relapsing-Remitting Multiple Sclerosis. Journal of Neuroscience Nursing, 33, 231-239. http://dx.doi.org/10.1097/01376517-200110000-00003

[18] Maikranz, J.M., Steele, R.G., Dreyer, M.L., Stratman, A.C. and Bovaird, J.A. (2006) The Relationship of Hope and Illness-Related Uncertainty to Emotional Adjustment and Adherence among Pediatric Renal and Liver Transplant Recipients. Journal of Pediatric Psychology, 32, 571-581. http://dx.doi.org/10.1093/jpepsy/jsl046

[19] DiMatteo, R.M. (2004) Variations in Patients’ Adherence to Medical Recommendations: A Quantitative Review of 50 Years of Research. Medical Care, 42, 200-209. http://dx.doi.org/10.1097/01.mlr.0000114908.90348.f9

[20] Bonsaken, T., Lerdal, A. and Fagermoen, A.S. (2012) Factors Associated with Self-Efficacy in Persons with Chronic Illness. Scandinavian Journal of Psychology, 53, 333-339. http://dx.doi.org/10.1111/j.1467-9450.2012.00959.x

[21] Breibart, W., Rosenfeld, B., Pessin, H., Kaim, M., Funesti-Esch, J., Galietta, M., Nelson, C.J. and Brescia, R. (2000) Depression, Hopelessness, and Desire for Hastened Death in Terminally Ill Patients with Cancer. JAMA, 284, 2907-2911. http://dx.doi.org/10.1001/jama.284.22.2907 
[22] Karasouli, E., Latchford, G. and Owens, D. (2014) The Impact of Chronic Illness in Suicidality: A Qualitative Exploration. Health Psychology and Behavioral Medicine, 2, 899-908. http://dx.doi.org/10.1080/21642850.2014.940954

[23] Williams, J.M.G. and Pollock, L.R. (2000) The Psychology of Suicidal Behaviour. In: Hawton, K. and van Heeringen, K., Eds., The International Handbook of Suicide and Attempted Suicide, John Wiley \& Sons Ltd., Chichester, 79-93. http://dx.doi.org/10.1002/9780470698976.ch5

[24] Herth, K. (1991) Development and Refinement of an Instrument to Measure Hope. Scholarly Inquiry for Nursing Practice: An International Journal, 5, 39-51.

[25] Babyak, M.A., Snyder, C.R. and Yoshino, L. (1993) Psychometric Properties of the Hope Scale: A Confirmatory Factor Analysis. Journal of Research in Personality, 27, 154-169. http://dx.doi.org/10.1006/jrpe.1993.1011

[26] Biesecker, B.B., Erby, L.H., Woolford, S., Adcock, J.Y., Cohen, J.S., Lamb, A., Lewis, K.V., Truitt, A. and Reeve, B.B. (2013) Development and Validation of the Psychological Adaptation Scale (PAS): Use in Six Studies of Adaptation to a Health Condition or Risk. Patient Education and Counseling, 93, 248-254. http://dx.doi.org/10.1016/j.pec.2013.05.006

[27] Kottner, J., Audigé, L., Brorson, S., Donner, A., Gajewski, B.J., Hróbjartsson, A., Roberts, C., Shoukri, M. and Streiner, D.L. (2011) Guidelines for Reporting Reliability and Agreement Studies (GRRAS) Were Proposed. Journal of Clinical Epidemiology, 64, 96-106. http://dx.doi.org/10.1016/j.jclinepi.2010.03.002

[28] Rosas, S.R. and Camphausen, L.C. (2007) The Use of Concept Mapping for Scale Development and Validation in Evaluation. Evaluation and Program Planning, 30, 125-135. http://dx.doi.org/10.1016/j.evalprogplan.2007.01.003

[29] DeVon, H.A., Block, M.E., Moyle-Wright, P., Ernst, D.M., Hayden, S.J., Lazzara, D.J., Savoy, S.M. and Kosta-Polston, E. (2007) A Psychometric Toolbox for Testing Validity and Reliability. The Journal of Nursing Scholarship, 39, 155-164. http://dx.doi.org/10.1111/j.1547-5069.2007.00161.x

[30] Soundy, A., Stubbs, B. and Roskell, C. (2014) The Experience of Parkinson’s Disease: A Systematic Review and Meta-Ethnography. The Scientific World Journal, 2014, Article ID: 613592. http://dx.doi.org/10.1155/2014/613592

[31] Soundy, A., Stubbs, B., Freeman, P., Coffee, C. and Roskell, C. (2014) Factors Influencing Patients' Hope in Stroke and Spinal Cord Injury: A Narrative Review. International Journal of Therapy and Rehabilitation, 21, 210-218. http://dx.doi.org/10.12968/ijtr.2014.21.5.210

[32] Soundy, A., Stubbs, B., Roskell, C., Fox, A., Williams, S. and Vancampfort, D. (2015) Identifying the Facilitators and Processes Which Influence Recovery in Individuals with Schizophrenia: A Systematic Review and Thematic Synthesis. Journal of Mental Health, 24, 103-110. http://dx.doi.org/10.3109/09638237.2014.998811

[33] Lawshe, C.H. (1975) A Quantitative Approach to Content Validity. Personnel Psychology, 28, 563-575. http://dx.doi.org/10.1111/j.1744-6570.1975.tb01393.x

[34] Soundy, A. and Elder, T. (2016) Developing and Applying the Theory of Psychological Adjustments Needs in Patients with Multiple Sclerosis. In: Watson, R., Ed., Multiple Sclerosis: Food and Lifestyle in Neurological Autoimmune, Elsevier, New York, 32.

[35] Lewis, H.A. and Kliewer, W. (1996) Hope, Coping and Adjustment among Children with Sickle Cell Disease: Tests of Mediator and Moderator Models. Journal of Pediatric Psychology, 21, 25-41. http://dx.doi.org/10.1093/jpepsy/21.1.25

[36] Lillis, J., Hayes, S.C., Bunting, K. and Masuda, A. (2009) Teaching Acceptance and Mindfulness to Improve the Lives of the Obese: A Preliminary Test of a Theoretical Model. Annals of Behavioral Medicine, 37, 58-69. http://dx.doi.org/10.1007/s12160-009-9083-x

[37] Hagerty, R.G., Butow, P.N., Ellis, P.M., Lobb, E.A., Pendlebury, S.C., Leighl, N., Mac Leod, C. and Tattersall, M.H. (2005) Communicating with Realism and Hope: Incurable Cancer Patients' Views on the Disclosure of Prognosis. Journal of Clinical Oncology, 23, 1278-1288. http://dx.doi.org/10.1200/JCO.2005.11.138

[38] Rideout, E. and Montemuro, M. (1986) Hope, Morale and Adaptation in Patients with Chronic Heart Failure. Journal of Advanced Nursing, 11, 429-438. http://dx.doi.org/10.1111/j.1365-2648.1986.tb01270.x

[39] Clayton, J.M., Hancock, K., Parker, S., Butow, P.N., Walder, S., Carrick, S., Currow, D., Ghersi, D., Glare, P., Hagerty, R., Olver, I.N. and Tattersall, M.H. (2008) Sustaining Hope When Communicating with Terminally Ill Patients and Their Families: A Systematic Review. Psycho-Oncology, 17, 641-659. http://dx.doi.org/10.1002/pon.1288

[40] Hasson-Ohayon, I., Kravetz, S., Meir, T. and Rozencwaig, S. (2009) Insight into Severe Mental Illness, Hope and Quality of Life of Persons with Schizophrenia and Schizoaffective Disorders. Psychiatry Research, 167, 231-238. http://dx.doi.org/10.1016/j.psychres.2008.04.019

[41] Isaksson, A.-K. and Ahlström, G. (2006) From Symptom to Diagnosis: Illness Experiences of Multiple Sclerosis Patients. Journal of Neuroscience Nursing, 38, 229-237. http://dx.doi.org/10.1097/01376517-200608000-00005

[42] Soundy, A., Roskell, C., Stubbs, B., Collett, J., Dawes, H. and Smith, B. (2014) Do You Hear What Your Patient Is Telling You? Understanding the Meaning behind the Narrative. Way Ahead, 18, 10-13. 
[43] Verhaeghe, S.T.L., Defloor, T. and Grypdonck, M.H.F. (2005) Stress and Coping among Families of Patients with Traumatic Brain Injury: A Review of the Literature. Journal of Clinical Nursing, 14, 1004-1012. http://dx.doi.org/10.1111/j.1365-2702.2005.01126.x

[44] Verhaeghe, S.T.L., Van Zuuren, F.J., Defloor, T., Duijnstee, M.S.H. and Grypdonck, M.H.F. (2006) How Does Information Influence Hope in Family Members of Traumatic Coma Patients in Intensive Care Unit? Journal of Clinical Nursing, 16, 1488-1497. http://dx.doi.org/10.1111/j.1365-2702.2006.01807.x

[45] Vansteenkiste, M. and Ryan, R.M. (2013) On Psychological Growth and Vulnerability: Basic Psychological Need Satisfaction and Need Frustration as a Unifying Principle. Journal of Psychotherapy Integration, 23, 263-280. http://dx.doi.org/10.1037/a0032359

[46] Leventhal, H., Meyer, D. and Nerenz, D. (1980) The Common-Sense Representation of Illness Danger. In: Rachman, S. Ed., Contributions to Medical Psychology, Vol. 2, Pergamon Press, New York, 7-30.

[47] Russell, J.A. (1980) A Circumplex Model of Affect. Journal of Personality and Social Psychology, 39, 1161-1178. http://dx.doi.org/10.1037/h0077714

[48] Hopman, P. and Rijken, M. (2015) Illness Perceptions of Cancer Patients: Relationships with Illness Characteristics and Coping. Psycho-Oncology, 24, 11-18. http://dx.doi.org/10.1002/pon.3591 


\section{Appendix 1. The Hope and Adaptation Scale (HAS)}

\section{Version 3.0}

Please answer the following questions relating to your process of adaptation and hope. The questions will relate to an aspect of your current situation that you are finding difficult to adapt too. Examples of this include adapting to the following; losses from a chronic illness, changes or losses in relationships in the work place, socially or at home, the inability to be independent, and the loss of an identity like being an athlete or father. Your own words will be used for the follow up assessments regarding this difficulty.

1. Please name the one aspect of your adaptation that you are finding most difficult?

Prompt: Importantly this question is about you and how you feel and what you consider to be difficult-there is no right or wrong answer.

I am finding most difficult to adapt to.

2. Regarding the difficulty you have identified how hopeful are you right now that you can or will overcome it?

Hope
Place a cross on the line where appropriate
I am completely sure/certain that it will be overcome
I believe it is likely I will overcome this
I accept that it might not be possible to overcome this
I feel uncertain and don't know if it is possible
I see no hope or ability to overcome

3. Regarding the difficulty you have identified do you feel able to adapt to it right now?

\section{Adaptation}

I am able to positively embracing this difficulty/my situation

I am able to accept this difficulty/my situation

I acknowledge this difficulty/my situation

I find it difficult to accept this difficulty/my situation

I reject and can not accept this difficulty/my situation 